\section{AB0209 THE CHANGES OF SIGNAL PEPTIDE- CUB-EGF DOMAIN-CONTAINING PROTEIN (SCUBE) AND OTHER ANGIOGENESIS PROTEINS DURING DISEASE ACTIVITY AND RELATIONSHIP WITH THE JOINT ULTRASOUND FINDINGS IN RHEUMATOID ARTHRITIS PATIENTS}

E. Capkin, N. Cılesızoglu, S. Ozer Yaman, M. Garıpoglu, D. Altay. Karadeniz Technical University, Trabzon, Turkey

Background: Rheumatoid arthritis (RA)is a multifactorial, systemic, progressive, inflammatory disease which is characterized with bone and cartilage destruction. Synovial angiogenesis is important at the etiopathology. SCUBE (Signal peptideCUB-EGF domain-containing protein) is rather a new surface cell protein. Its secretion increases with inflammation and hypoxic conditions. Its relations with inflammation and angiogenesis are shown in preclinical studies.

Objectives: The purpose is to study levels of newly identified plasmaSCUBE 1 and 3 and other angiogenesis markers and analysis of changes after treatment in RA patients. Moreover, to determine whether a correlation with this change in SCUBE proteins after treatment, clinical parameters and with joint ultrasound findings.

Methods: This study covers patients diagnosed with RA associated with 2010 American Collage of Rheumatology (ACR) diagnosis criteria matched with healthy controllers who are equivalent of RA patients in terms of age and gender. Detailed background information and examination of the patients were recorded and disease activity scores (DAS28) were figured out and US7 scores were calculated. The levels of SCUBE 1-3, Vascular Endotedial Groving Factor (VEGF), Matrix metaloproteinaz-9 (MM-9), Interlökin-6 (IL-6), CD40L were evaluated with the method of Enzyme-Linked ImmunoSorbent Assay (ELISA). Clinical and laboratory measurements were re-evaluated at the third month after treatment. Results: This study covers 56 individuals; 28 of whom were diagnosed with RA and 28 of them were healthy controllers. Significant differences were observed between RA patients and healthy controller groups in terms of MMP-9 levels $(p<0,05)$. Levels of SCUBE-1, SCUBE-3, VEGF, IL-6 ve CD-40 were similar $(p>0,05)$.After treatment VEGF levels were significantly lower compared to pretreatment $(p<0,05)$, the changes in SCUBE-1, SCUBE-3, IL-6, CD-40 ve MMP-9 levels were not statistically significant $(p>0.05)$. After treatment ultrasound scores were significantly lower than before treatment $(p<0.05)$

Conclusions: In our study, significant improvements were observed in clinical, laboratory and ultrasound findings after treatment. MMP-9 and VEGF were associated with disease activity. SCUBE proteins which have been newly identified markers of angiogenesis were shown no relationship with disease activity.

References:

[1] Szekanecz Z, Besenyei T, Paragh G, Koch AE Angiogenesis in rheumatoid arthritis.Autoimmunity. 2009:7:563-731.

[2] Yanga M, Mingyang G, Yonghe $H$ Jiang y. Scube regulates synovial angiogenesis-related signaling. Medical Hypotheses 2013;27: 948-953.

[3] Lainer-Carr D, Brahn E. Angiogenesis inhibition as a therapeutic approach for inflammatory synovitis. Nat Clin Pract Rheumatol. 2007;3:434-42.

Disclosure of Interest: None declared

DOI: 10.1136/annrheumdis-2017-eular.5949

\section{AB0210 THE MULTI-BIOMARKER DISEASE ACTIVITY SCORE FOR ASSESSING RESPONSE TO TREATMENT WITH ADALIMUMAB}

D. Pappas ${ }^{1,2}$, E.H. Sasso ${ }^{3}$, R.J. Bolce ${ }^{3}$, X. Liu ${ }^{3}$, C.J. Etzel ${ }^{1,4} \cdot{ }^{1}$ CORRONA

LLC, Southborough; ${ }^{2}$ Columbia University Medical Center, New York;

${ }^{3}$ Crescendo Bioscience Inc., South San Francisco; ${ }^{4}$ University of Texas MD

Anderson Cancer Center, Houston, United States

Background: The multi-biomarker disease activity (MBDA) score measures 12 serum biomarkers to assess disease activity in patients with rheumatoid arthritis (RA) on a scale of $1-100$. The MBDA score was validated in several different cohorts but has not been evaluated in a cohort consisting only of patients initiating TNF inhibitor therapy in clinical practice. We utilized patients enrolled in the Corrona-CERTAIN study to evaluate MBDA scores for patients initiating adalimumab (ADA) in several clinical practices in the US.

Objectives: Evaluate the ability of the MBDA score to assess response to treatment with ADA.

Methods: We studied 106 biologic-naïve RA patients who had been treated with ADA for at least 12 months, had initiated ADA in CERTAIN while in moderate or high disease activity by CDAI, and for whom sera were available at baseline $(\mathrm{BL})$ and Months 3 and 6 . Changes $(\Delta)$ in MBDA score and DAS28-CRP were evaluated from $\mathrm{BL}$ to Months 3 and 6 by the one-sample paired t-test. $\triangle \mathrm{MBDA}$ scores were evaluated for patients grouped by EULAR response categories, using the Cochran-Armitage test for trend. Receiver Operating Characteristic (ROC) analysis with bootstrap sampling (20,000 iterations) was used to evaluate MBDA score ability to discriminate $\triangle \mathrm{DAS} 28-\mathrm{CRP}$ improvement $>1.2$ units at Month 3 , and to determine the optimal MBDA threshold by maximizing the sum of sensitivity and specificity (Youden's index criterion).

Results: At BL, median values were age 54.5 years, disease duration 2 years, BMI 28.2, DAS28-CRP 4.7, CDAI 24, SDAI 25.4; 74.5\%/65.4\% were RF+/ACPA+. Median MBDA score was 49 with $17(16 \%)$ patients in low $(<30), 23(22 \%)$ patients in moderate $(30-44)$, and $66(62 \%)$ patients in high $(>44)$ MBDA categories. The relative magnitude and the direction of median change from $\mathrm{BL}$ to Months 3 and 6 were similar for MBDA score $(-8,-9)$ and DAS28-CRP $(-1.4,-1.8)$, with statistically significant changes from $B L$ for each (line graphs in Figure). Similar results were observed for SDAI and CDAI. Pearson's correlations with $\triangle$ MBDA score at Months 3 and 6 were $0.58,0.59$, respectively, for $\triangle D A S 28$ CRP; $0.48,0.47$ for $\triangle \mathrm{SDAl}$; and $0.42,0.42$ for $\triangle \mathrm{CDAl}$ (all $\mathrm{p}<0.0001$ ). Median reductions in MBDA score were significantly greater for patients with concurrent DAS28-CRP improvement $>1.2$ units $(n=67)$ vs. $\leq 1.2$ units $(n=39)$ at Month 3 (15 vs. 2) and Month 6 (13 vs. 1.5) (both $p<0.0001$ ); and for patients with EULAR Good vs. Moderate vs. Non-responses $(p=0.0002$ at Month $3, p<0.0001$ at Month 6) (bar graphs in Figure). Area under the ROC curve (AUROC) for the ability of $\triangle$ MBDA score from BL to Month 3 to discriminate DAS28-CRP improvement $>1.2$ units at Month 3 was $0.82(95 \% \mathrm{Cl}, 0.74-0.90)$. The optimal threshold for this discrimination was a reduction in MBDA score $>9$ units, with sensitivity/specificity=0.63/0.82 and PPV/NPV $=0.86 / 0.56$.

Figure. Median changes from baseline in MBDA score and DAS28-CRP at 3 and 6 months: in line graphs with 95\% CI (above) and by EULAR response category months:
(below).

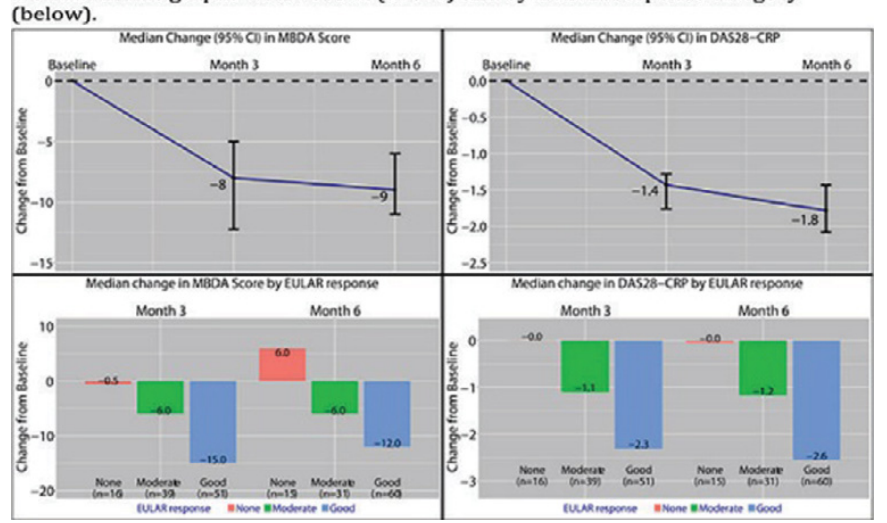

Conclusions: This study expands the previous validation of the MBDA score by demonstrating its ability to assess response to treatment with adalimumab in a US clinical practice cohort. The AUROC value of 0.82 for discriminating improvements in DAS28-CRP $>1.2$ units indicates a significant association between change in MBDA score and clinical improvement.

Disclosure of Interest: D. Pappas Grant/research support from: AbbVie, Consultant for: AbbVie, Employee of: CORRONA, LLC, E. Sasso Shareholder of: Myriad Genetics, Inc., Employee of: Crescendo Bioscience Inc., R. Bolce Shareholder of: Myriad Genetics, Inc., Employee of: Crescendo Bioscience Inc., X. Liu Shareholder of: Myriad Genetics, Inc., Employee of: Crescendo Bioscience Inc., C. Etzel Consultant for: Merck, Employee of: CORRONA, LLC DOI: 10.1136/annrheumdis-2017-eular.5602

\section{AB0211 THE EFFECT OF SMOKING, ALCOHOL AND CAFFEINE ON EARLY RHEUMATOID ARTHRITIS OUTCOMES}

E. Chamizo-Carmona ${ }^{1}$, C. Carrasco Cubero ${ }^{2}$, J.J. Aznar Sanchez ${ }^{1}$, R. Veroz Gonzalez ${ }^{1}$, P.J. Cossío Jimenez ${ }^{1}$, S.M. Rojas Herrera ${ }^{1} .{ }^{1}$ Rheumatology, $H$. Merida, Merida; ${ }^{2}$ Rheumatology, CHU Badajoz, Badajoz, Spain

Background: The aim of early RA treatment is remission. Intensive treatment with MTX achieve remission in $30-50 \%$ patients (pts). Modifiable risk factors, as smoking, alcohol, coffee and tea, may affect response to MTX.

Objectives: To study the influence of tobacco, alcohol, caffeine on the MTX response in early RA pats.

Methods: A case-control study (2010-2015): cases were pts who achieved DAS28<2.6 (remission) and controls were pts who did not. We collected information from pts $>18$ years with early RA, treated with MTX, evaluated quarterly in a specialized unit early RA. All the pts underwent a structured interview about their smoking history and others habits. A descriptive and comparative study, was performed (SPSS21)

Results: 182 pts (age 50,96 $\pm 13,11$ y, 67,6\% female, 81,3\% FR+ and 65,7\% ACPA+) was treated with MTX and followed 105,03 $\pm 7,15$ months since 1995 . More than $95 \%$ pts received MTX (in rapid escalation) in the first 24 months of the onset of symptoms. DAS28<2.6 was achieved for $67(36,8 \%)$ pts, who required an lower average dose of $\operatorname{MTX}(15,07 \mathrm{mg} / \mathrm{w})$ than those who did not $(18,04 \mathrm{mg} / \mathrm{w})(\mathrm{p}=0,000)$. Age, DAS28 and physical function at baseline, treatment delay, smoking and adverse events by MTX were related to remission. The univariate and multivariate analysis of the baseline pts characteristics and the relationship of their smoking history with age, RF, ACPA and outcome of MTX monotherapy are shown in table 1and 2, respectively. The median survival of MTX monotherapy was 87,39 months ( 100.27 non-smokers and 47.70 months for current smokers (Log Rank 10.32, p 0.001) (see graphic).

Conclusions: The treatment of early RA with MTX alone achieved high rates of remission, especially in non-smokers. Smoking cessation could significantly improve the response to MTX and therefore should be an integral part of the treatment of early RA patients. 
Abstract AB0211 - Table 1

\begin{tabular}{|c|c|c|c|c|}
\hline \multirow[t]{2}{*}{ Baseline Characteristic } & \multicolumn{3}{|c|}{ Univariate analysis } & \multirow{2}{*}{$\begin{array}{c}\text { Multivariate analysis } \\
\text { OR }(95 \% \mathrm{Cl})\end{array}$} \\
\hline & DAS28<2.6 & No remission & OR $(95 \%$ IC) & \\
\hline Age, mean (SD), years & $55.46(13.21)$ & $48.34(12.38)$ & $7.11(3.26,10.96)^{\star \star}$ & 0.124 \\
\hline Female, $\mathrm{n}(\%)$ & $41(33.3)$ & $82(66.7)$ & ns & 0.173 \\
\hline Current smoking, $\mathrm{n}(\%)$ & $12(21.4 \%)$ & $54478.6)$ & $2,84(1.37-5.89)^{\star \star}$ & $0.37(0.16,0.86)^{*}$ \\
\hline Caffeine, $\mathrm{n}(\%)$ & $33(29,2 \%)$ & $80(70,8)$ & $2.35(1.26-4.39)^{\star \star}$ & 0.092 \\
\hline Functional status $>\ln (\%)$ & $38(29.0 \%)$ & $93(71.0)$ & $3,23(1.65-6.31)^{\star *}$ & $2.39(1.06,5.40)^{\star}$ \\
\hline Extra-articular involv, n (\%) & $7(20,6 \%)$ & $27(79.4)$ & $2,63(1.08-6.43)^{*}$ & 0.107 \\
\hline MTX adverse events, $\mathrm{n}(\%)$ & $20(24,1 \%)$ & $63(75,9)$ & $2.85(1.50-5.40)^{\star *}$ & $0.44(0.20,0.95)^{\star}$ \\
\hline Baseline DAS28PCR, mean (SD) & $3.88(0.56)$ & $4,75(0,76)$ & $-0,87(-1.06,-0.67)^{\star \star}$ & $5.79(2.99,11.20)^{\star \star}$ \\
\hline MTX delay, mean (SD), m & $1.66(3.91)$ & $5,39(18.57)$ & $-3.73(-7.28,-0.18)^{\star}$ & 0.089 \\
\hline
\end{tabular}

Abstract AB0211 - Table 2

\begin{tabular}{|c|c|c|c|c|c|c|}
\hline Smoking history & Edad & ACPA & MTX dose & Remission $(n=67)$ & Low activity $(\mathrm{n}=98)$ & Need for biological $(n=60)$ \\
\hline $\begin{array}{l}\text { Never Smoking ( } n=67), \%(S D) \text {, } \\
\quad \text { diff }(95 \% \mathrm{Cl})\end{array}$ & $\begin{array}{c}53,85(15.23)^{\star} \\
4.58(0.32 \text { to } 8.82)\end{array}$ & $\begin{array}{c}126.03(146.91)^{\star} \\
-3.97(-103.03 \text { to }-4.90)\end{array}$ & $\begin{array}{c}16,86(3.92) \\
n s\end{array}$ & $\begin{array}{c}28(41.8) \\
\text { ns }\end{array}$ & $\begin{array}{c}39(58.2) \\
n s\end{array}$ & $\begin{array}{c}19(28.4) \mathrm{ns} \\
\mathrm{ns}\end{array}$ \\
\hline $\begin{array}{l}\text { Former Smoker }(\mathrm{n}=59), \%(\mathrm{SD}) \text {, } \\
\quad \operatorname{diff}(95 \% \mathrm{Cl})\end{array}$ & $\begin{array}{c}65.97(58.68) \\
n s\end{array}$ & $\begin{array}{c}188.81(159.17) \\
n s\end{array}$ & $\begin{array}{c}15.97(3.34)^{\star} \\
-1.44(-0.29 \text { to }-2.59)\end{array}$ & $\begin{array}{c}27(45.8) \\
n s\end{array}$ & $\begin{array}{c}39(66.1)^{\star} \\
1.67(1.06 \text { to } 2.63)\end{array}$ & $\begin{array}{c}14(23.3) \\
\mathrm{ns}\end{array}$ \\
\hline $\begin{array}{l}\text { Current smoker }(n=56), \%(S D) \text {, } \\
\quad \text { diff }(95 \% \mathrm{Cl})\end{array}$ & $\begin{array}{c}45.34(9.94)^{\star *} \\
-8.11(-2.02 \text { to }-4.12)\end{array}$ & $\begin{array}{c}171.03(166.99) \\
\text { ns }\end{array}$ & $\begin{array}{c}18.08(3.63)^{\star \star} \\
1.63(2.79 \text { to } 0.47)\end{array}$ & $\begin{array}{c}12(21.4)^{\star \star} \\
0.46(.26 \text { to } 0.82)\end{array}$ & $\begin{array}{c}20(35.7)^{\star \star} \\
0.47(0.3 \text { to } 0.75)\end{array}$ & $\begin{array}{c}27(48.2)^{\star \star} \\
2.62(1.36 \text { to } 5.06)\end{array}$ \\
\hline
\end{tabular}

${ }^{*} p<0.05,{ }^{* *} p<0.01$.

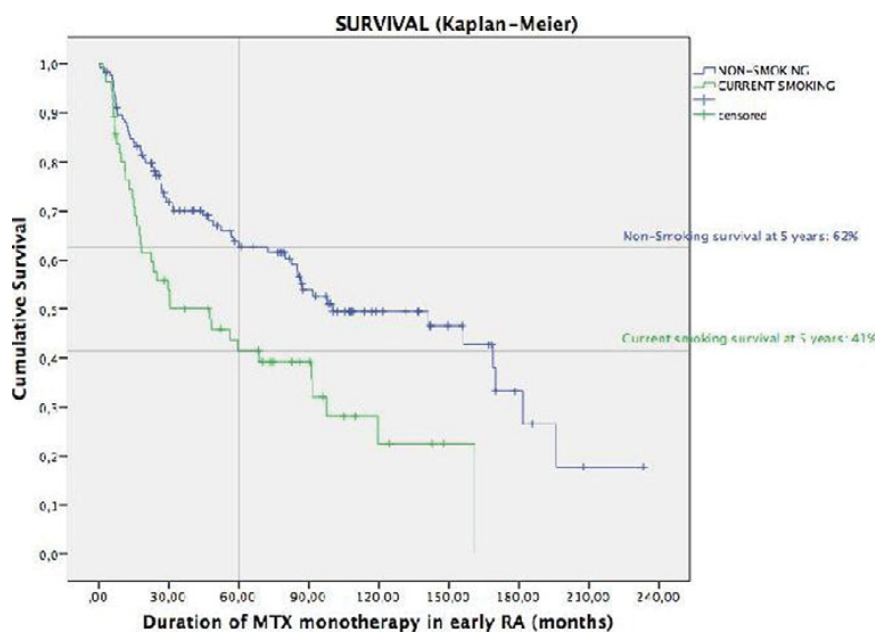

References:

[1] Söderlin, et al. Scandinavian Journal of Rheumatology. 2011;40(4):249-55.

Disclosure of Interest: None declared

DOI: 10.1136/annrheumdis-2017-eular.6739

\section{AB0212 CLINICAL AND SOCIODEMOGRAPHIC CHARACTERISTICS ASSOCIATED WITH RESPONSE TO METHOTREXATE (MTX) IN A COHORT OF PATIENTS WITH RHEUMATOID ARTHRITIS (RA) NAÏVE TO DMARD}

E. Chamizo-Carmona ${ }^{1}$, C. Carrasco Cubero ${ }^{2}$, P.J. Cossio Jimenez ${ }^{1}$, S.M. Rojas Herrera $^{1}$, T.L. Rodriguez Araya ${ }^{1}$, R. Veroz Gonzalez ${ }^{1}$, J.J. Aznar Sanchez ${ }^{1}$.

${ }^{1}$ Rheumatology, Hospital de Merida, Merida; ${ }^{2}$ Rheumatology, CHU Badajoz, Badajoz, Spain

Background: RA treatment involves starting early with a DMARD. MTX achieves good sustained response in $30-40 \%$ of patients (pts). When MTX response is insufficient add other DMARD by achieve RA remission. Different factors may affect the response to MTX

Objectives: To analyze the clinical and demographic characteristics related to response to MTX in RA pts DMARD-naïve

Methods: We enrolled between 2011 and 2015, pts > 18years RA diagnosed (ACR 1987 criteria), treated firs with MTX monotherapy (MTXm). A case-control study (MTXm persistence with CRP-DAS28 $<3.2$ and suspension of MTXm by ineffectiveness or toxicity, respectively) was performed. We collected information that can influence the response to MTXm by medical records review and patient survey. A descriptive and analitical study with SPSS statistics 21 was performed Results: We included 222 pts (70 men and 152 women). The characteristics of cases (123) and controls (99) are shown in the table. The causes of MTXm suspension were remission (7), intolerance/toxicity (19) and inefficiency (79). MTX was discontinued in $40(18.2 \%)$ pts, $28(12.7 \%)$ of them by intolerance/toxicity. Of $123(55.4 \%)$ responders, $71(32.0 \%)$ were CRP-DAS28<2.6. MTXm response was associated with age at onset $\geq 60$ years $(x 218.47, p<0.01$, OR 3.67), rheumatoid factor (RF) $<100 \mathrm{IU}(\times 2$ 10.92, $\mathrm{p}<0.01, \mathrm{OR} 3.16)$ and current smoking ( $x 212.71, p<0.01, \mathrm{OR} 2.95)$. Tobacco was associated with $\mathrm{RF}+(x 28.9$ $p<0.01$ OR $2.59(1.37 ; 4.89)$ and ACPA+ $(x 24.49 p<0.05$ OR $1.88(1.04,3.38)$. We found no association with gender, education, job, coffee, tea or alcoho drinks, comorbidities, cardiovascular risk, possitivity ACPA or FR, RA presentation, treatment delay, or corticosteroid use. We found no correlation between age of
RA-onset and RF or ACPA levels and MTXm duration. MTXm persistence at 5 years was $59 \%$ pts and their median survival was 93 months (77.14 to 108.8). We only found significant differences in favor of non-smokers and $\mathrm{RF}<100$

Table 1. Clinical and sociodemographics characterisitics of RA patients

\begin{tabular}{|c|c|c|c|}
\hline Characteristics & $\begin{array}{c}\text { Responders } \\
\mathrm{n}=125\end{array}$ & $\begin{array}{c}\text { Nonresponders } \\
\mathrm{n}=99\end{array}$ & Statistic Significancy \\
\hline Age at onset (y) (mean, SD) & $53.48(13.0)$ & $46.65(11.5)$ & $t=4.08 p=00006$ \\
\hline Female $\mathrm{n}(\%)$ & $80(65.0)$ & $72(72.7)$ & ns \\
\hline Current Smokers n (\%) & $23(18.7)$ & $40(40.4)$ & $\begin{array}{l}x^{2} 12.7(p<0,01) \\
\text { OR } 2.95(1.6,5.4)\end{array}$ \\
\hline Alcohol consumers $\mathrm{n}(\%)$ & $35(28.5)$ & $28(28.3)$ & ns \\
\hline Comorbidity n (\%) & $92(74.8)$ & $61(61.6)$ & $\begin{array}{l}\chi^{2} 4.45(p<0.05) \\
\text { OR } 1.21(1.0,1.5)\end{array}$ \\
\hline $\mathrm{CV}$ risk factors $\mathrm{n}(\%)$ & $92(74.8)$ & $81(81.8)$ & ns \\
\hline Polyarticular onset of AR $n(\%)$ & $61(49.6)$ & $61(61.6)$ & ns \\
\hline Extraarticular involvement $\mathrm{n}(\%)$ & $17(13.8)$ & $21(21.2)$ & ns \\
\hline Possitive RF n (\%) & $89(72.4)$ & 79 (79.8) & ns \\
\hline Possitive ACPA n (\%) & $70(60.3)$ & $64(68.1)$ & ns \\
\hline Duration of RA (m) (mean (SD) & $96.1(63.1)$ & $96,0(73.9)$ & ns \\
\hline MTX toxicity n (\%) & $47(38.2)$ & $59(59.6)$ & $\begin{array}{c}\chi^{2} 10.0(p<0.01) \\
\text { OR } 2.38(1.4,4.1))\end{array}$ \\
\hline MTX dose $(\mathrm{mg})$ (mean, SD) & $15.6(0.32)$ & $17.8(0.37)$ & $\mathrm{t}=-4.52 \mathrm{p}=00001$ \\
\hline
\end{tabular}

Conclusions: The initial treatment of RA with MTX is an effective and safe option, with a high drug survival. MTX response was not associated with antibody positivity (RF or ACPA), but it was significantly better in non-smokers patients and $\mathrm{RF}<100$. Smoking cessation could significantly improve the response to MTX of RA patients

References:

[1] Saevarsdottir S, et al. Arthritis Rheum 2011;63:26-36.

[2] V. K. Ranganath et al. Rheumatology 2013;52:1809-1817.

Disclosure of Interest: None declared

DOI: 10.1136/annrheumdis-2017-eular.1109

\section{AB0213 HIGH POWER DOPPLER SIGNALS SEEMS MORE IMPORTANT THAN SYNOVITIS SCORES IN ESTABLISHED RHEUMATOID ARTHRITIS}

E.D. Keskin ${ }^{1}$, F.G. Yurdakul ${ }^{2}$, H. Bodur ${ }^{2}$, A. Akıncı Tan ${ }^{3}$, L. Özçakar ${ }^{3} .{ }^{1}$ Physical Medicine and Rehabilitation, Kırıkkale University Faculty of Medicine, Kırıkkale; ${ }^{2}$ Physical Medicine and Rehabilitation, Ankara Numune Training and Research Hospital; ${ }^{3}$ Physical Medicine and Rehabilitation, Hacettepe University Faculty of Medicine, Ankara, Turkey

Background: Rheumatoid arthritis (RA) is a chronic systemic inflammatory disease characterized by synovial inflammation, potential cartilage and bone damages. Evaluation with ultrasound (US) has come into prominence due to conventional radiography is relatively insensitive on soft tissue inflammatory changes and early bone erosions $(1,2)$.

Objectives: The value of US has been shown in early arthritis, but is not well known for established RA. The aim of this study is to determine the relation between US signal, disease activity, articular damage and disability in established RA patients.

Methods: Forty-four RA patients (21 women, 23 men) were enrolled to the study. Age and gender, duration of disease, morning stiffness, disease activity score 28 (DAS28), The Rheumatoid Arthritis Articular Damage (RAAD) score, Hand disability Index (HDI), DASH (Disabilities of the Arm, Shoulder and Hand) scale, and grip strength values were recorded. Wrist, I-II- III. metacarpophalangeal and proximal interphalangeal joints of dominant hand were examined by both $\mathrm{B}$ mode US (BMOD) and Power Doppler US (PDUS).

Results: All of the 44 patients were established RA. The median of disease 